\title{
Proline, Total Antioxidant Capacity, and OsP5CS Gene Activity in Radical and Plumule of Rice are Efficient Drought Tolerance Indicator Traits
}

\author{
Muhammad Abu Bakar Saddique (iD, , ${ }^{1,2}$ Zulfiqar Ali $\left(\mathbb{D},{ }^{1,2}\right.$ Muhammad Ali Sher (D), \\ Babar Farid (D), ${ }^{1}$ Rao Muhammad Ikram (iD, ${ }^{3}$ and Muhammad Saeed Ahmad (iD) ${ }^{2}$ \\ ${ }^{1}$ Institute of Plant Breeding and Biotechnology, MNS University of Agriculture, Multan 60000, Pakistan \\ ${ }^{2}$ Department of Plant Breeding and Genetics, University of Agriculture, Faisalabad 38040, Pakistan \\ ${ }^{3}$ Department of Agronomy, MNS University of Agriculture, Multan 60000, Pakistan \\ Correspondence should be addressed to Zulfiqar Ali; zulfiqarpbg@hotmail.com
}

Received 18 August 2020; Revised 14 September 2020; Accepted 24 November 2020; Published 22 December 2020

Academic Editor: Vera Popovic

Copyright (c) 2020 Muhammad Abu Bakar Saddique et al. This is an open access article distributed under the Creative Commons Attribution License, which permits unrestricted use, distribution, and reproduction in any medium, provided the original work is properly cited.

\begin{abstract}
The success of a plant breeding program is linked with the rapid screening of crop germplasm. In the following study, the germination stage of rice seeds has been examined for the rapid screening of drought-tolerant genotypes. The rice genotypes (10 drought tolerant, 5 moderately drought tolerant, and 5 drought susceptible) were sown in Petri dishes under control and osmotic stress of 15\% PEG6000. Data were recorded after four days of sowing for the osmotic stress-induced change in imbibition rate, speed of germination, radical and plumule length, radical and plumule total fresh and dry weight, proline contents, total antioxidant capacity, and malondialdehyde level in radical and plumule of seeds. Moreover, the change in expression of OsP5CS gene was also recorded in one of each drought tolerant, moderately drought tolerant, and drought susceptible genotypes. Under osmotic stress, the level of proline, total antioxidant capacity, and the expression of OsP5CS were increased in drought-tolerant genotypes as compared to moderately drought tolerant and drought susceptible genotypes. While, the change in imbibition rate, speed of germination, radical and plumule length, and fresh and dry weight were not symmetrical in drought tolerant, moderately drought tolerant, and drought susceptible genotypes. In short, the symmetrical change in proline, total antioxidant capacity, and expression of OsP5CS gene within radical and plumule of drought tolerant, moderately drought tolerant, and drought susceptible genotypes can help rapid screening of drought-tolerant rice genotypes.
\end{abstract}

\section{Introduction}

In the near future, water shortage will prevail, and it is projected that by 2025 , almost 15 million hectares of the land will suffer physical water scarcity and 22 million hectares of economic water scarcity. The web of impacts becomes so extensive that it will be difficult to determine accurate financial estimates of damages. It will bring agricultural drought and ultimately the food insecurity [1-3]. Moistureloving plants that are part of our diet need special attention to be acclimatized in low water agriculture of the future. At present, the success in developing a protocol for the rapid screening of drought-tolerant genotypes can help to ensure food security during future agricultural droughts.

Rice is one of the important water-loving plants that feeds more than half of the world population. It needs special attention to be fit in future water-scarce agriculture. Drought stress damages rice plants at all growth stages. It decreases the germination rate, germination potential, the germination energy, seedling vigor, coleoptile length, fresh shoot weight, fresh root weight, root length, shoot length, and leaf area [3-6]. It also decreases the number of effective tillers per hill, number of spikelets per panicle, filled grains per hill, 1000 -grain weight, grain yield, and seed quality [7-9]. It 
increases the level of cellular compatible solutes (soluble sugars, sugar alcohols, organic acids, glycine betaine, proline, trehalose, and organic acid), growth substances (auxins, cytokinins, gibberellins, ethylene, and ABA), and antioxidants (peroxidase, catalase, superoxide dismutase, glutathione reductase, ascorbate peroxidase, ascorbic acid, reduced glutathione, $\gamma$-aminobutyric acid, and $\alpha$-tocopherol). It induces high expression of stress-responsive genes. It also triggers cell membrane damage and thus boosts the cellular level of malondialdehyde (MDA) [10-17]. In short, drought stress disturbs plant homeostasis at each developmental stage from germination till maturity. While the extent of damage varies from genotype to genotype. Drought-tolerant genotypes (DT) successfully ameliorate the effects of these injuries, while susceptible genotypes show significant loss in the abovementioned traits [15, 18, 19]. Therefore, the extent of damage in these traits is used as a scale for the screening of DT genotypes.

The relative significance of these traits varies, and some traits are more distinctive than others. Plant biomass and the synthesis of proline as well as antioxidants are more prominent drought tolerance indicator traits $[14,16,20]$. Proline acts as a compatible solute, scavenger of the reactive oxygen species, and energy source to ameliorate the damages of osmotic shocks. It also has protein-stabilizing properties and stimulates protein folding under unfavorable conditions [21-23]. Likewise, antioxidants prevent the damage of reactive oxygen species and thus maintain cellular physiological functioning, whereas the synthesis of MDA occurs as a result of membrane damage [24-28]. Under drought stress, the level of proline and antioxidants remain high in DT genotypes, while MDA contents remain low in DT genotypes [29-31]. The synthesis pattern of these biochemicals can help effective screening of crop germplasm.

For increasing the speed of plant breeding programs, germplasm screening at the germination stage is very much important. It has the potential to provide reliable drought tolerance indicator traits. But most of the work performed about the screening of plant germplasm focuses on the seedling and maturity stages, while the germination stage has not been deeply explored. What is performed on the germination stage mostly focuses on morphological parameters [32-34], but molecular and biochemical traits are needed to be explored further. In present research work, the radicle and plumule of germinating rice seeds were examined based on the drought-induced change in morphological, biochemical, and molecular parameters. That provided drought tolerance indicator traits which are helpful for the rapid and reliable screening of rice germplasm.

\section{Materials and Methods}

2.1. Plant Material and Growing Conditions. The 20 droughtresponsive genotypes (10 drought tolerant, five moderately drought tolerant (MDT), and five drought susceptible (DS)) were used in this study (Table 1). These 20 genotypes were selected from the screening of 606 rice accessions (details are given in supplementary material, Table S1, Figure S1). The drought responsiveness of these 20 genotypes was proved both at seedling and maturity stages (Figure S2). The seeds of each genotype were sown between filter papers placed in Petri dishes. The experiment was conducted at the lab bench $\left(28^{\circ} \mathrm{C}\right)$ following the factorial under a complete randomized design. Two treatment combinations (control and drought) each with three replications were maintained. Five $\mathrm{ml}$ of distilled water $\left(\mathrm{dH}_{2} \mathrm{O}\right)$ was applied in control treatments, and $5 \mathrm{ml}$ of $15 \%$ PEG6000 solution in $\mathrm{dH}_{2} \mathrm{O}(-2.95$ bars of osmotic potential) was applied in drought treatments. The experiment was monitored for four days until both the radical and plumule gained almost one $\mathrm{cm}$ length.

2.2. Traits Understudy. The genotypes were evaluated based on the drought-induced change in the imbibition rate after $24 \mathrm{~h}$ and $48 \mathrm{~h}$ (IR $\mathrm{mg} / \mathrm{g}$ ), the speed of germination (SG), radical length $(\mathrm{cm})$, plumule length $(\mathrm{cm})$, radical and plumule total fresh weight $(\mathrm{g})$, radical and plumule total dry weight, proline level (ppm), total antioxidant capacity (TAC) (nm), MDA contents ( $\mathrm{nmol} / \mathrm{ml})$, and expression of OsP5CS gene. The IR was determined by the formula of Wang et al. [35] and SG by Ellis and Roberts [36].

$$
\operatorname{IR}\left(\frac{\mathrm{mg}}{\mathrm{g}}\right)=\left(\frac{W 2-W 1}{W 1}\right) \times 1000
$$

where $W_{1}(\mathrm{~g})$ represents the dry seed weight, and $W_{2}(\mathrm{~g})$ represents the seed weight after imbibition.

$$
\begin{aligned}
\text { SG }= & \frac{\text { Number of germinated seeds }}{\text { Days of the first count }}+\cdots \\
& +\frac{\text { number of germinated seeds }}{\text { days of final count }} .
\end{aligned}
$$

Changes in IR and SG were determined by the following formula.

$$
\begin{gathered}
\% \text { change in IR }=\left(\frac{\text { IR under control }- \text { IR under osmotic stress }}{\text { IR under control }}\right) \times 100, \\
\% \text { change in SG }=\left(\frac{\text { SG under control }- \text { SG under osmotic stress }}{\text { SG under control }}\right) \times 100 \text {. }
\end{gathered}
$$

2.3. Determination of Proline ( $p$ pm). It was determined by following the method of Bates et al. [37]. The $0.5 \mathrm{~g}$ of the fresh radical and plumule was homogenized in $5 \mathrm{ml}$ of $3 \%$ aqueous sulphosalicylic acid. This homogenate was filtered through Whatman No. 2 filter paper. One ml of filtrate was taken in a test tube, and it was mixed with $1 \mathrm{ml}$ of acid 
ninhydrin and $1 \mathrm{ml}$ of glacial acetic acid. The mixture was briefly vortexed and heated at $100^{\circ} \mathrm{C}$ in a waterbath. Samples were removed from the waterbath after one hour, and the reaction was terminated on ice. Four $\mathrm{ml}$ of toluene was added to the solution and vortexed for 15-20 seconds. The chromophore containing free proline was aspirated from the aqueous phase in a test tube and warmed to room temperature. The spectrophotometer absorbance was taken at $520 \mathrm{~nm}$. Drought-induced change in proline formation was determined by the following formula.

Difference in proline formation $(\mathrm{ppm})=$ proline in stressed explants - proline in control explants.

2.4. Determination of Total Antioxidant Capacity. It was determined by following the method of Prieto et al. [38]. The $0.4 \mathrm{~g}$ of fresh radical and plumule was homogenized in $50 \%$ methanol and centrifuged at $12,000 \times \mathrm{g}$ for at least $15 \mathrm{~min}$. The $100 \mu \mathrm{l}$ of enzyme extract (supernatant) and $900 \mu \mathrm{l}$ reagent $\left(0.6 \mathrm{MH}_{2} \mathrm{SO}_{4}, 28 \mathrm{mM}\right.$ sodium phosphate, and $4 \mathrm{mM}$ ammonium molybdate) were mixed and boiled at $95^{\circ} \mathrm{C}$ for $30 \mathrm{~min}$. Spectrophotometer absorbance was measured at $695 \mathrm{~nm}$; higher the value of absorbance indicates more TAC [39]. Drought-induced change in TAC was determined by the following formula.

$$
\begin{aligned}
\text { The difference in TAC }(\mathrm{nm})= & \text { TAC of stressed explants } \\
& - \text { TAC of control explants. }
\end{aligned}
$$

2.5. Determination of Malondialdehyde. It was determined by following the method of Heath and Packer [40]. The $0.1 \mathrm{~g}$ fresh radical and plumule was homogenized in $1 \mathrm{ml}$ of $5 \%$ trichloroacetic acid (TCA) and centrifuged at $12,000 \times \mathrm{g}$ for at least $15 \mathrm{~min}$. One $\mathrm{ml}$ supernatant was mixed with an equal volume of reagent $(0.5 \%$ thiobarbituric acid in $20 \%(\mathrm{w} / \mathrm{v})$ TCA). The mixture was boiled for $30 \mathrm{~min}$ at $95^{\circ} \mathrm{C}$, cooled, and centrifuged at $7500 \times \mathrm{g}$ for $5 \mathrm{~min}$. The spectrophotometer absorbance of the mixture was recorded at $532 \mathrm{~nm}$ and $600 \mathrm{~nm}$. Nonspecific turbidity was adjusted by subtracting the absorbance at $600 \mathrm{~nm}$ from that taken at $532 \mathrm{~nm}$.

$$
\operatorname{MDA}\left(\frac{\mathrm{nmol}}{\mathrm{ml}}\right)=\left(\frac{A_{532}-A_{600}}{155000}\right) \times 10^{6} .
$$

$A_{532}$ is the absorption value at $532 \mathrm{~nm}$, and $A_{600}$ is the absorption value at $600 \mathrm{~nm}$. While $155000 \mathrm{nmol} / \mathrm{ml}$ is the absorption coefficient for MDA [40]. Drought-induced change in MDA was determined by the following formula

$$
\text { Difference in MDA production }\left(\frac{\mathrm{nmol}}{\mathrm{ml}}\right)=\mathrm{MDA} \text { in stressed explants }- \text { MDA in control explants. }
$$

2.6. Expression of OsP5CS. For the expression analysis, three out of 20 genotypes were tested, including one DT (WC297), one MDT (Caawa), and one DS (IR-64). The expression analysis of OsP5CS was performed from the homogenized sample of radicle and plumule after four days of sowing. For primers designing, coding DNA sequences were retrieved from the Rice Annotation Project Database (http:// rapdb.dna.affrc.go.jp/). Ubiquitin (UBQ) was used as a reference gene. Forward and reverse primers of these two genes are given in Table S5. TRIzol ${ }^{\circledR}$ reagent (Favorgen Biotech Corp.) was used for the extraction of RNA from a mixed sample of radical and plumule. High-quality RNA was used to synthesize cDNA following the protocol of Thermo Fisher Scientific. Gel band strength was studied with Image. J. IJ 1.46r. Numerical values showing gel band strength were used to calculate the percentage change in the expression of OsP5CS.

$\%$ change in gene expression $=\left(\frac{\text { Gel band strength under osmotic stress }- \text { gel band strength under control }}{\text { Gel band strength under control }}\right) \times 100$. 
TABLE 1: Drought-responsive genotypes $1-10$ are DT, $11-15$ are MDT, and 16-20 are DS.

\begin{tabular}{lccc}
\hline Sr. No. & Code & Designation & Origin \\
\hline 1 & 168 & WC-297 & China \\
2 & 86 & KSK-22 & Pakistan \\
3 & 354 & Bombon & Spain \\
4 & 355 & Breviaristata & Portugal \\
5 & 434 & 519 & Uruguay \\
6 & 435 & Jambu & Indonesia \\
7 & 436 & Azucena & Philippines \\
8 & 445 & Kalubala Vee & Sri Lanka \\
9 & 488 & Pate Blanc MN 1 & Côte D’Ivoire \\
10 & 510 & Sadri Belyi & USSR \\
11 & 362 & Caawa & Taiwan \\
12 & 325 & Jamir & Bangladesh \\
13 & 429 & Guan-Yin-Tsan & China \\
14 & 475 & Lemont & USA \\
15 & 404 & Hiderisirazu & Japan \\
16 & 421 & Gharib & Iran \\
17 & 85 & Maguinsalay & Philippines \\
18 & 153 & 30 A & Pakistan \\
19 & 43 & IR-64 & Philippines \\
20 & 329 & 9524 & Peru \\
\hline
\end{tabular}

DT, drought tolerant; MDT, moderately drought tolerant; DS, drought susceptible.

2.7. Statistical Analysis. Data were analyzed using the analysis of variance method (Statistix 8 , version 8.1) and biplot analysis [41].

\section{Results}

3.1. Imbibition Rate and Speed of Germination. The IR and SG were significantly decreased under osmotic stress $(p \leq 0.01$, Table S2). After $24 \mathrm{~h}$ of osmotic stress, IR was decreased in all DT, MDT, and DS genotypes (Figure 1(a)). In DT genotypes, the average decrease was $7.9 \%$, and in MDT and DS genotypes, it was $20.0 \%$ and $20.4 \%$, respectively. While, under optimum water supply, the average value of IR in DT genotypes was $359 \mathrm{mg} / \mathrm{g}$; in MDT genotypes, it was $328 \mathrm{mg} / \mathrm{g}$; and in DS genotypes, it was $362 \mathrm{mg} / \mathrm{g}$. Under drought stress, average IR was $330 \mathrm{mg} / \mathrm{g}$ in DT genotypes, $262 \mathrm{mg} / \mathrm{g}$ in MDT genotypes, and $288 \mathrm{mg} / \mathrm{g}$ in DS genotypes. Similarly, the decrease in IR was also recorded after $48 \mathrm{~h}$ (Figure 1(b)). In DT genotypes, the average decrease was $7.8 \%$; in MDT genotypes, it was $6.4 \%$, and in DS genotypes, it was $11.4 \%$. While, under optimum water environment, the average value of IR in DT genotypes was $472 \mathrm{mg} / \mathrm{g}$; in MDT genotypes, it was $489 \mathrm{mg} / \mathrm{g}$; and in DS genotypes, it was $467 \mathrm{mg} / \mathrm{g}$. Under drought stress, average IR was $434 \mathrm{mg} / \mathrm{g}$ in DT genotypes, $458 \mathrm{mg} / \mathrm{g}$ in MDT genotypes, and $414 \mathrm{mg} / \mathrm{g}$ in DS genotypes. Drought also decreased the germination rate, and it resulted in a significant decrease in SG for all genotypes. Some genotypes from DT, MDT, and DS groups had almost the same SG, and there was no distinction for this decrease in these genotypes (Figure 1(c)). Up to $55.8 \%$ average decrease was recorded in DT genotypes, $52.5 \%$ in MDT genotypes, and $48.4 \%$ in DS genotypes. While, under optimum water supply, the average value of the
SG in DT genotypes was 2.8; in MDT genotypes, it was 2.9; and in DS genotypes, it was 3.4. Under drought stress, average SG was 1.2 in DT genotypes, 1.4 in MDT genotypes, and 1.7 in DS genotypes.

3.2. Radical and Plumule Length and Biomass. Radical length, plumule length, radical and plumule TFW, and radical and plumule TDW were significantly decreased under osmotic stress ( $p \leq 0.01$, Table S2). There was no trend recorded in DT, MDT, and DS genotypes for this decrease. Biplot in Figure 2 shows the gain in radical and plumule length, radical and plumule total fresh weight, and radical and plumule total dry weight under control and osmotic stress environments. Genotypes were randomly scattered around trait vectors; there was no grouping of DT, MDT, and DS genotypes based on these traits. The OP length of the DT, MDT, and DS genotypes was random for all mentioned traits, i.e., if it was high for a DT genotype, at the same time, it was also high for MDT and DS genotypes.

Under optimum water supply, the average value of the radical length in DT genotypes was $1.09 \mathrm{~cm}$; in MDT genotypes, it was $1.06 \mathrm{~cm}$; and in DS genotypes, it was $1.08 \mathrm{~cm}$. Under drought stress, the value of the radical length was $0.6 \mathrm{~cm}$ in DT genotypes, $0.6 \mathrm{~cm}$ in MDT genotypes, and $0.62 \mathrm{~cm}$ in DS genotypes. Under optimum water supply, the average value of the plumule length in DT genotypes was $0.91 \mathrm{~cm}$; in MDT genotypes, it was $0.9 \mathrm{~cm}$; and in DS genotypes, it was $0.9 \mathrm{~cm}$. Under drought stress, the value of the plumule length was $0.6 \mathrm{~cm}$ in DT genotypes, $0.65 \mathrm{~cm}$ in MDT genotypes, and $0.64 \mathrm{~cm}$ in DS genotypes. Under optimum water supply, the average value of the total fresh weight in DT genotypes was $0.035 \mathrm{~g}$; in MDT genotypes, it was $0.04 \mathrm{~g}$; and in DS genotypes, it was $0.04 \mathrm{~g}$. Under drought stress, the value of the total fresh weight was $0.017 \mathrm{~g}$ in DT genotypes, $0.022 \mathrm{~g}$ in MDT genotypes, and $0.021 \mathrm{~g}$ in DS genotypes. Under optimum water supply, the average value of the total dry weight in DT genotypes was $0.007 \mathrm{~g}$; in MDT genotypes, it was $0.009 \mathrm{~g}$; and in DS genotypes, it was $0.009 \mathrm{~g}$. Under drought stress, the value of the total dry weight was $0.003 \mathrm{~g}$ in DT genotypes, $0.004 \mathrm{~g}$ in MDT genotypes, and $0.004 \mathrm{~g}$ in DS genotypes. At the germination stage, the morphological traits were unable to classify genotypes into DT, MDT, and DS groups. Therefore, these traits do not have the potential for the screening of drought-tolerant rice genotypes.

3.3. Proline Contents. Under osmotic stress, a significant and symmetrical change was recorded for the synthesis of biochemicals in DT, MDT, and DS genotypes $(p \leq 0.01$, Table S2). These biochemicals were able to classify rice genotypes into three groups of DT, MDT, and DS genotypes. The level of proline in radical and plumule of DT genotypes was quite higher than MDT and much higher than DS genotypes. The average increase of proline contents in DT genotypes was $9.2 \mathrm{ppm}$. In MDT and DS genotypes, it was $6.4 \mathrm{ppm}$ and $0.056 \mathrm{ppm}$, respectively. Under optimum water supply, the average value of proline in DT genotypes was $8.0 \mathrm{ppm}$; in MDT genotypes, it was $7.8 \mathrm{ppm}$; and in DS 


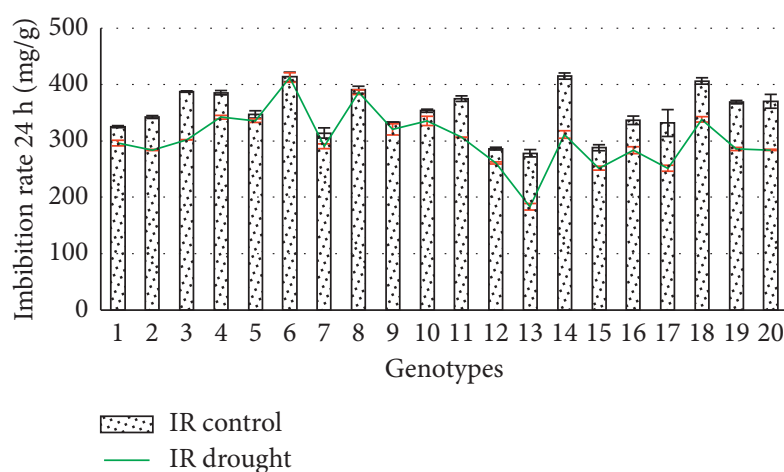

(a)

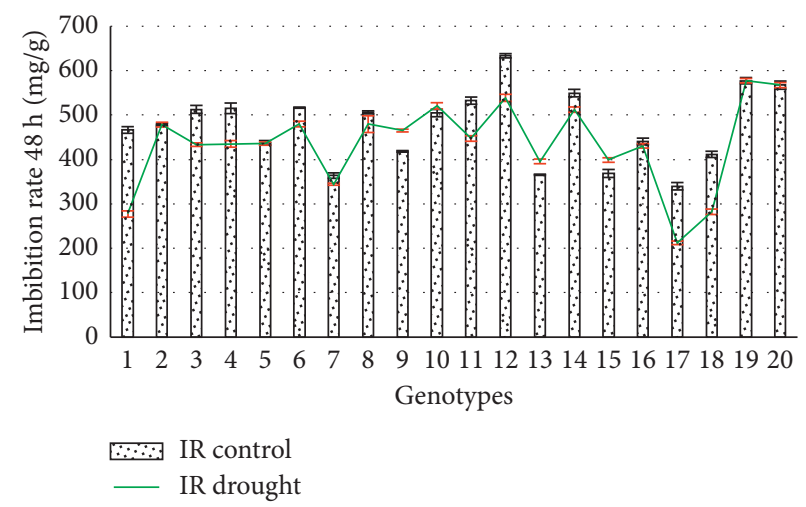

(b)

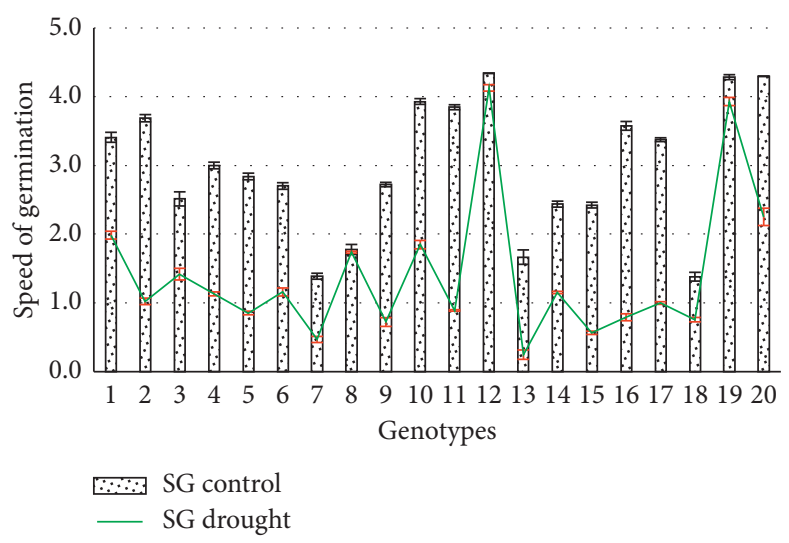

(c)

FIgURE 1: Genotypic response at the germination stage. (a) Imbibition rate (IR mg/g) after 24 hours of sowing. (b) IR (mg/g) after 48 hours of sowing. (c) The speed of germination (SG) after four days of sowing. At the horizontal axis, 1-20 numbers show the genotypes. 1-10 are drought tolerant, 11-15 are moderately drought tolerant, and 16-20 are drought susceptible.

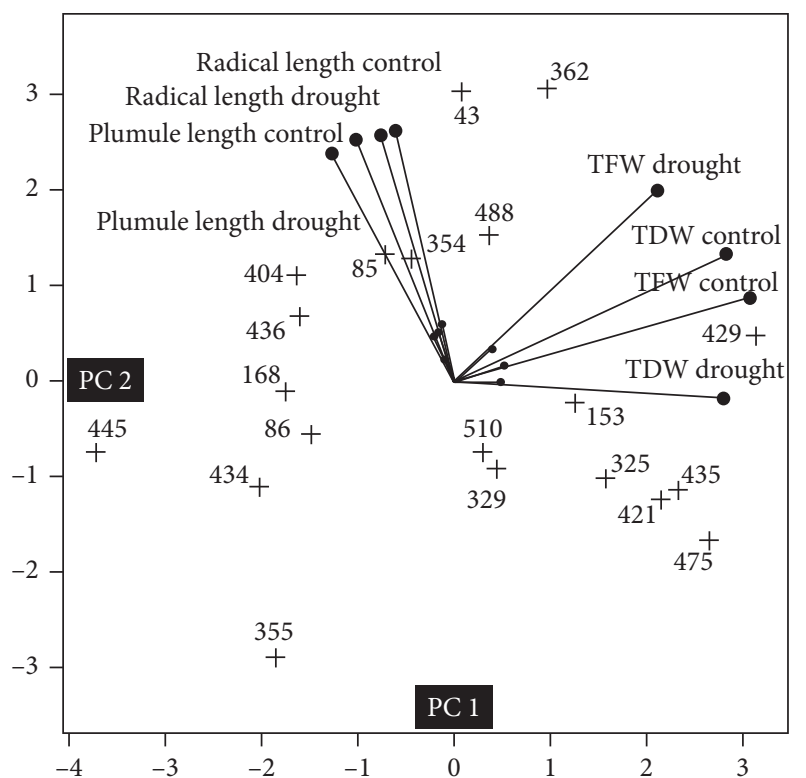

FIGURE 2: Biplot analysis for the gain in radical and plumule length and radical and plumule total fresh weight (TFW) and total dry weight (TDW) under control and drought environments. genotypes, it was $8.12 \mathrm{ppm}$. While, under drought stress, the average value of proline in DT genotypes was $17.2 \mathrm{ppm}$; in MDT genotypes, it was $14.2 \mathrm{ppm}$; and in DS genotypes, it was $8.2 \mathrm{ppm}$. It shows that the higher level of proline was produced in DT genotypes. Figure 3(a) shows the droughtinduced increase in proline formation of the twenty genotypes at the germination stage.

3.4. Total Antioxidant Capacity. In osmotic stress, TAC was significantly changed in DT, MDT, and DS genotypes $(p \leq 0.01$, Table S2). In the radical and plumule of DT genotypes, the TAC was higher than MDT and much higher than DS genotypes. The average increase in TAC in DT genotypes was $0.17 \mathrm{~nm}$. While in MDT and DS genotypes, it was $0.14 \mathrm{~nm}$ and $0.037 \mathrm{~nm}$, respectively. Under optimum water supply, the average value of TAC in DT genotypes was $0.34 \mathrm{~nm}$; in MDT genotypes, it was $0.35 \mathrm{~nm}$; and in DS genotypes, it was $0.35 \mathrm{~nm}$. While, under drought stress, the average value of TAC in DT genotypes was $0.51 \mathrm{~nm}$; in MDT genotypes, it was $0.49 \mathrm{~nm}$; and in DS genotypes, it was $0.39 \mathrm{~nm}$. Figure 3(b) shows the drought-induced increase in TAC of twenty genotypes at the germination stage. 


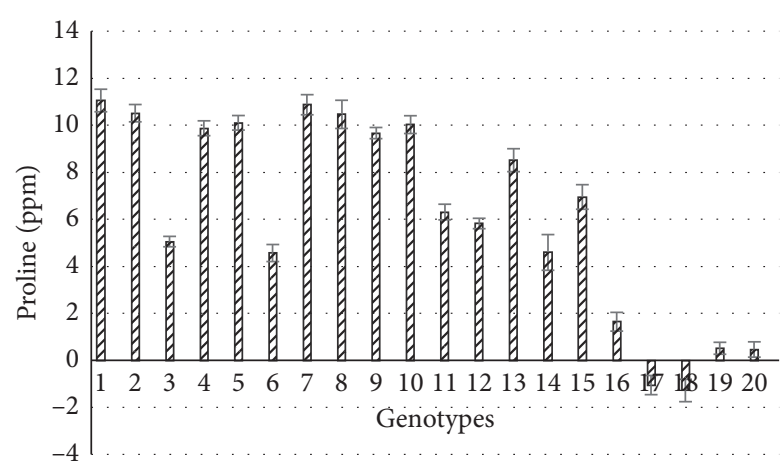

(a)

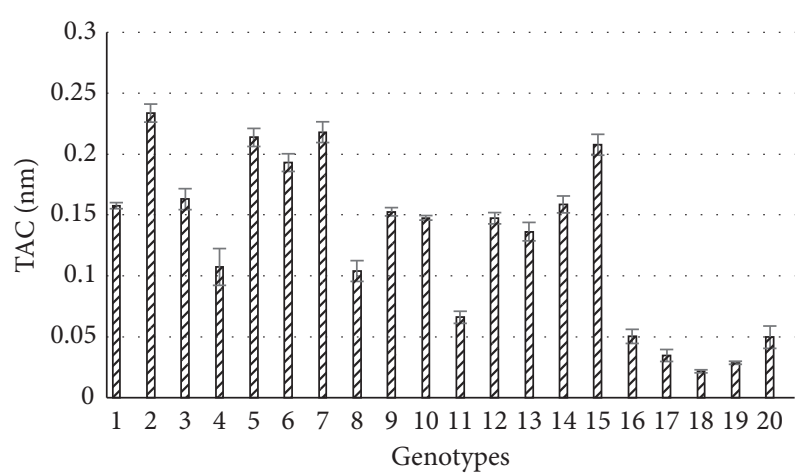

(b)

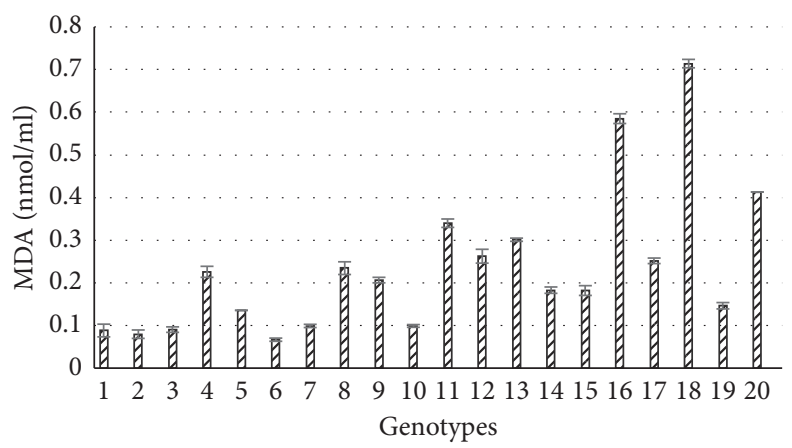

(c)

FIGURE 3: Drought-induced change in the production of biochemical. (a) Variation in the production of proline. (b) Increase in total antioxidant capacity (TAC). (c) Increase in the formation of malondialdehydes (MDA). On the horizontal line, 1-20 numbers show the rice genotypes. 1-10 are drought tolerant, 11-15 are moderately drought tolerant, and 16-20 are drought susceptible.

3.5. Malondialdehyde Contents. The production of MDA is an indicator of plant membrane damage. Under osmotic stress, a significant change was recorded for the production of MDA contents in DT, MDT, and DS genotypes $(p \leq 0.01$, Table S2). It was seen that under osmotic stress, increase in the production of MDA was minimum in DT genotypes and maximum in DS plants. The average change in level of MDA in radical and plumule of DT, MDT, and DS genotypes was $0.13 \mathrm{nmol} / \mathrm{ml}, 0.25 \mathrm{nmol} / \mathrm{ml}$, and $0.42 \mathrm{nmol} / \mathrm{ml}$, respectively. Under optimum water supply, the average value of MDA in DT genotypes was $0.14 \mathrm{nmol} / \mathrm{ml}$; in MDT genotypes, it was $0.168 \mathrm{nmol} / \mathrm{ml}$; and in DS genotypes, it was $0.177 \mathrm{nmol} / \mathrm{ml}$. While, under drought stress, the average value of MDA in DT genotypes was $0.39 \mathrm{nmol} / \mathrm{ml}$; in MDT genotypes, it was $0.511 \mathrm{nmol} / \mathrm{ml}$; and in DS genotypes, it was $0.612 \mathrm{nmol} / \mathrm{ml}$. Figure 3(c) shows the drought-induced increase in MDA production of twenty genotypes at the germination stage.

3.6. Transcript Abundance of OsP5CS. The expression of the OsP5CS gene was consistent with the biochemical results of proline formation. In osmotic stress, the expression of OsP5CS was increased in DT and MDT genotypes, while in DS, no increase was recorded. Figure 4 shows the variation in the expression of the OsP5CS gene; higher the intensity of gel bands shows a higher level of the gene expression, and it is related to a higher peak of the graph. In DT genotypes, the increase in expression of OsP5CS was 24\%, in MDT genotypes, expression was 33\%, and in DS genotypes, expression was decreased by $1.7 \%$.

\section{Discussion}

The success of a plant breeding program is highly associated with an efficient and fast germplasm screening protocol. These protocols are always needed by the plant breeders which are to meet the challenges of continuously changing climate. The unpredictable climate scenario fails the modern cultivars or even elite lines before these are released for general cultivation $[42,43]$. These failed cultivars are needed to be replaced with the same speed as they are eliminated. To substitute the eliminated cultivars, rapid germplasm screening protocols are needed. In the present study, we reported that the pace of rice germplasm screening against drought stress can be increased by using the osmotic stressinduced change in proline contents, TAC, and the expression of OsP5CS in the radical and plumule of seeds as drought tolerance indicator traits. It was also observed that the morphological traits such as IR, SG, radical and plumule length, and fresh and dry weight were not able to screen drought-tolerant rice genotypes; therefore, these were not considered as efficient drought tolerance indicator traits. These morphological traits have extensively been used for the screening of germplasm [44-47]. But the present research has proved that these morphological traits are less 


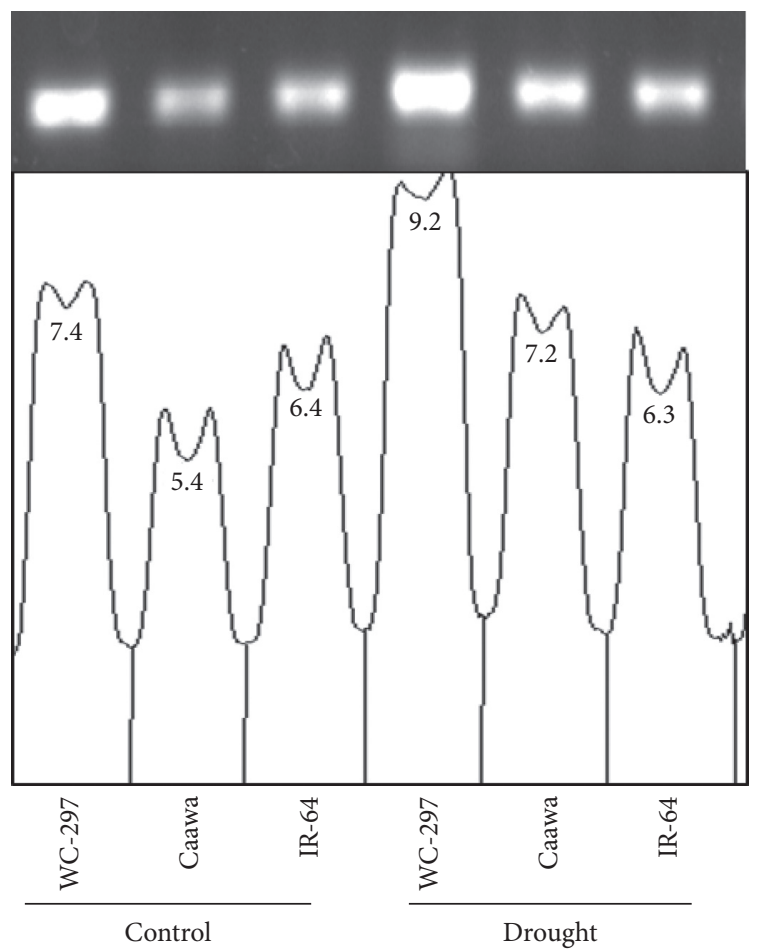

Figure 4: Drought-induced change in the expression of OsP5CS. A significant change in the expression of OsP5CS was recorded for drought tolerant (WC-297), moderately drought tolerant (Caawa), and drought susceptible (IR-64) genotypes.

effective than the biochemical traits for the rice germplasm screening against drought stress.

The importance of the proline as a marker for screening drought-responsive plant material has already been extensively acknowledged. When plants are exposed to water shortage, the production of proline increases. This increase sometimes reaches 100 times more than the normal synthesis rate [48-51]. We concluded that the drought-induced change in proline contents in radical and plumule can screen germplasm at the germination stage. We reported that the osmotic stress boosted TAC in radical and plumule of the DT genotypes which may be an efficient drought tolerance indicator trait for the rapid screening of germplasm. Similarly, the previous studies show that whenever droughttolerant genotypes sense osmotic stress, their TAC increases and help them to scavenge the ROS $[52,53]$. The third biochemical parameter for the screening of drought-responsive genotypes was MDA contents. The production of MDA indicates the damage to cell membranes. The droughtinduced increase in MDA production has already been reported and considered as a criterion to estimate the cell membrane injuries $[28,48,54]$. We found that under osmotic stress, the MDA level in DS genotypes was higher than in MDT and DT genotypes. It was not considered as a good biochemical indicator trait as were proline and TAC because in some DT, MDT, and DS genotypes, the MDA contents were almost similar. Therefore, it was concluded that the changes in proline production and TAC are efficient drought tolerance indicator traits. Moreover, the DT genotypes selected based on these traits remain tolerant until maturity (Figure S2). In short, these traits have true potential to speed up the process of rice germplasm screening.

Semi-Q PCR-based expression study of proline producing gene OsP5CS has confirmed the role of proline for screening germplasm at the germination stage. The expression pattern was quite similar to the pattern of proline production accessed through biochemical analysis. Under osmotic stress, the expression was quite higher in DT and MDT genotypes than in DS genotypes. Similarly, the increase in the expression of OsP5CS has been reported in many plants, and it is cited that the expression of OsP5CS increases in plants under water shortages. This increase in expression helps plants to produce more proline which saves plants from the shocks of desiccation $[48,55]$. Based on these experimental results, it was summarized that the syntheses of proline and TAC or the expressions of the OsP5CS gene in radical and plumule of rice seeds are best drought tolerance indicator traits and may serve the task of rapid and reliable screening of rice germplasm.

\section{Data Availability}

The raw data supporting the conclusions of this manuscript will be made available by the authors, without undue reservation, to any qualified researcher.

\section{Disclosure}

The work described has not been published previously in any journal.

\section{Conflicts of Interest}

The authors declare that they have no conflicts of interest.

\section{Authors' Contributions}

MABS, RMI, and ZA conceived and designed the experiments. MABS and MSA performed the experiments. MABS, RMI, BF, MAS, and ZA analyzed the data. ZA contributed reagents/materials/analysis tools and involved in critical review and editing. MABS, BF, and MAS wrote the paper.

\section{Acknowledgments}

The authors thank the Higher Education Commission of Pakistan for financing this research work, through Indigenous Fellowship (Pin No. 213-66438-2Av2-077 and project \# 2161 and 2297). The authors also thank International Rice Research Institute, Philippines, National Agriculture Research Centre, Pakistan, and Rice Research Institute, Kala Shah Kaku, Pakistan, for providing rice germplasm.

\section{Supplementary Materials}

Table S1. Mean square of absolute values for various seedling traits of 606 rice genotypes grown in control and drought stress. Table S2. Mean square of absolute values for various germination traits of 20 rice genotypes grown in control and 
osmotic stress. Table S3. Mean square of absolute values for various seedling traits of 20 rice genotypes grown in control and drought stress. Table S4. Mean square of absolute values for various maturity traits of 20 rice genotypes grown in control and drought stress. Table S5. Forward and reverse primers of the genes under study. Figure S1. Biplots for the screening of rice germplasm. Biplot showing the gain in root length (RL), shoot length (SL), fresh root weight (FRW), fresh shoot weight (FSW), dry root weight (DRW), and dry shoot weight (DSW) under control and drought environments. Figure S2. (a) Biplot for the genotypic evaluation at the seedling stage. It is showing the relationship between genotypes and traits including RL (root length), SL (shoot length), FRW (fresh root weight), FSW (fresh shoot weight), DRW (dry root weight), and DSW (dry shoot weight) under control and drought stress. (b) Biplot for the genotypic evaluation at the maturity stage. It is showing the relationship between genotypes and traits including fertile florets (FF), the number of tillers (Ti), plant total biomass (PTB), and 100-grain weight (100-GW) under control and drought stress. (Supplementary Materials)

\section{References}

[1] P. V. V. Prasad, S. R. Pisipati, I. Momčilović, and Z. Ristic, "Independent and combined effects of high temperature and drought stress during grain filling on plant yield and chloroplast EF-Tu expression in spring wheat," Journal of Agronomy and Crop Science, vol. 197, no. 6, pp. 430-441, 2011.

[2] A. Dai, "Increasing drought under global warming in observations and models," Nature Climate Change, vol. 3, no. 1, p. 52, 2013.

[3] J. Liu, H. Yang, S. N. Gosling et al., "Water scarcity assessments in the past, present, and future," Earth's Future, vol. 5, no. 6, pp. 545-559, 2013.

[4] H. Pirdashti, Z. T. Sarvestani, G. Nematzadeh, and A. Ismail, "Effect of water stress on seed germination and seedling growth of rice (Oryza sativa L.) genotypes," Journal of Agronomy, vol. 2, no. 4, pp. 217-222, 2003.

[5] H. S. Garg and C. Bhattacharya, "Drought tolerance indices for screening some of rice genotypes," IJABR, vol. 7, pp. 671-674, 2017.

[6] W. Xu, W. Tang, C. Wang et al., "SiMYB56 confers drought stress tolerance in transgenic rice by regulating lignin biosynthesis and ABA signaling pathway," Frontiers in Plant Science, vol. 11, p. 785, 2020.

[7] F. Kızılgeçi, N. Tazebay, M. Namlı, Ö. Albayrak, and M. Yildirım, "The drought effect on seed germination and seedling growth in bread wheat (Triticum aestivum L.)," International Journal of Agriculture, Environment and Food Sciences, vol. 1, pp. 33-37, 2017.

[8] M. Sharifunnessa and M. T. Islam, "Effect of drought stress at different growth stages on yield and yield components of six rice (Oryza sativa L.) genotypes," Fundamental and Applied Agriculture, vol. 2, pp. 285-289, 2017.

[9] S. M. A. Rahman and R. H. Ellis, "Seed quality in rice is most sensitive to drought and high temperature in early seed development," Seed Science Research, vol. 29, pp. 238-249, 2019.

[10] K. Shinozaki and K. Yamaguchi-Shinozaki, "Gene networks involved in drought stress response and tolerance," Journal of Experimental Botany, vol. 58, no. 2, pp. 221-227, 2007.
[11] M. Usman, Z. Raheem, T. Ahsan, A. Iqbal, Z. N. Sarfaraz, and Z. Haq, "Morphological, physiological and biochemical attributes as indicators for drought tolerance in rice (Oryza sativa L.)," European Journal of Biological Sciences, vol. 5, pp. 23-28, 2013.

[12] M. B. Sokoto and A. Muhammad, "Response of rice varieties to water stress in Sokoto, Sudan Savannah, Nigeria," Journal of Biosciences and Medicines, vol. 02, no. 01, p. 68, 2014.

[13] P. M. Yang, Q. C. Huang, G. Y. Qin, S. P. Zhao, and J. G. Zhou, "Different drought-stress responses in photosynthesis and reactive oxygen metabolism between autotetraploid and diploid rice," Photosynthetica, vol. 52, no. 2, pp. 193-202, 2014.

[14] M. Maghsoodi and J. Razmjoo, "Identify physiological markers for drought tolerance in alfalfa," Agronomy Journal, vol. 107, no. 1, pp. 149-157, 2015.

[15] V. Pandey and A. Shukla, "Acclimation and tolerance strategies of rice under drought stress," Rice Science, vol. 22, no. 4, pp. 147-161, 2015.

[16] M. A. B. Saddique, Z. Ali, A. S. Khan, I. A. Rana, and I. H. Shamsi, "Inoculation with the endophyte Piriformospora indica significantly affects mechanisms involved in osmotic stress in rice," Rice, vol. 11, p. 34, 2018.

[17] S. Nasrin, S. Saha, H. H. Begum, and R. Samad, "Impacts of drought stress on growth, protein, proline, pigment content and antioxidant enzyme activities in rice (Oryza sativa L. var. BRRI dhan-24)," Dhaka University Journal of Biological Sciences, vol. 29, no. 1, pp. 117-123, 2020.

[18] M. M. Islam, E. Kayesh, E. Zaman, T. A. Urmi, and M. M. Haque, "Evaluation of rice (Oryza sativa L.) genotypes for drought tolerance at germination and early seedling stage," The Agriculturists, vol. 16, no. 1, pp. 44-54, 2018.

[19] K. Neelam, G. K. Sahi, K. Kumar, and K. Singh, "Identification of drought stress tolerance in wild species germplasm of rice based on leaf and root morphology," Plant Genetic Resources: Characterization and Utilization, vol. 16, no. 4, pp. 289-295, 2018.

[20] S. A. Zafar, A. Hameed, M. Ashraf, A. S. Khan, X. Li, and K. H. Siddique, "Agronomic, physiological and molecular characterisation of rice mutants revealed the key role of reactive oxygen species and catalase in high-temperature stress tolerance," Functional Plant Biology, vol. 47, no. 5, pp. 440-453, 2020a.

[21] M. T. Fisher, "Proline to the rescue," Proceedings of the National Academy of Sciences, vol. 103, no. 36, pp. 13265-13266, 2006.

[22] Z. Ignatova and L. M. Gierasch, "Inhibition of protein aggregation in vitro and in vivo by a natural osmoprotectant," Proceedings of the National Academy of Sciences, vol. 103, no. 36, pp. 13357-13361, 2006.

[23] F. R. Vanani, L. Shabani, M. R. Sabzalian, F. Dehghanian, and L. Winner, "Comparative physiological and proteomic analysis indicates lower shock response to drought stress conditions in a self-pollinating perennial ryegrass," PLoS One, vol. 15, Article ID e0234317, 2020.

[24] S. S. Gill and N. Tuteja, "Reactive oxygen species and antioxidant machinery in abiotic stress tolerance in crop plants," Plant Physiology and Biochemistry, vol. 48, no. 12, pp. 909930, 2010.

[25] S. Hayat, Q. Hayat, M. N. Alyemeni, A. S. Wani, J. Pichtel, and A. Ahmad, "Role of proline under changing environments," Plant Signaling \& Behavior, vol. 7, no. 11, pp. 1456-1466, 2012.

[26] E. Tommasino, S. Griffa, K. Grunberg et al., "Malondialdehyde content as a potential biochemical indicator of tolerant 
Cenchrus ciliaris L. genotypes under heat stress treatment," Grass and Forage Science, vol. 67, no. 3, pp. 456-459, 2012.

[27] D. M. Kasote, S. S. Katyare, M. V. Hegde, and H. Bae, "Significance of antioxidant potential of plants and its relevance to therapeutic applications," International Journal of Biological Sciences, vol. 11, no. 8, p. 982, 2015.

[28] F. Khan, P. Upreti, R. Singh, P. K. Shukla, and P. A. Shirke, "Physiological performance of two contrasting rice varieties under water stress," Physiology and Molecular Biology of Plants, vol. 23, no. 1, pp. 85-97, 2017.

[29] S. Abbas, S. Ahmad, S. Sabir, and A. Shah, "Detection of drought tolerant sugarcane genotypes (Saccharum officinarum) using lipid peroxidation, antioxidant activity, glycinebetaine and proline contents," Journal of Soil Science and Plant Nutrition, vol. 14, pp. 233-243, 2014.

[30] Z. Kamarudin, M. Yusop, M. Tengku Muda Mohamed, M. Ismail, and A. Harun, "Growth performance and antioxidant enzyme activities of advanced mutant rice genotypes under drought stress condition," Agronomy, vol. 8, no. 12, p. 279, 2018.

[31] M. Laxa, M. Liebthal, W. Telman, K. Chibani, and K.-J. Dietz, "The role of the plant antioxidant system in drought tolerance," Antioxidants, vol. 8, no. 4, p. 94, 2019.

[32] A. A. Khan, I. A. Khan, and M. A. Azmat, "Comprehensive screening and selection of okra (Abelmoschus esculentus) germplasm for salinity tolerance at the seedling stage and during plant ontogeny," Journal of Zhejiang University Science $B$, vol. 13, pp. 533-544, 2012.

[33] J. Anbumalarmathi and P. Mehta, "Effect of salt stress on germination of indica rice varieties," European Journal of Biological Science, vol. 6, pp. 1-6, 2013.

[34] H. Wu, J. Guo, C. Wang et al., "An effective screening method and a reliable screening trait for salt tolerance of Brassica napus at the germination stage," Frontiers in Plant Science, vol. 10, p. 530, 2019.

[35] Z.-f. Wang, J.-f. Wang, Y.-m. Bao, Y.-y. Wu, X. Su, and H.-s. Zhang, "Inheritance of rice seed germination ability under salt stress," Rice Science, vol. 17, no. 2, pp. 105-110, 2010.

[36] R. Ellis and E. Roberts, The Quantification of Ageing and Survival in Orthodox Seeds, Seed Science and Technology, Netherlands, 1981.

[37] L. S. Bates, R. P. Waldren, and I. D. Teare, "Rapid determination of free proline for water-stress studies," Plant and Soil, vol. 39, no. 1, pp. 205-207, 1973.

[38] P. Prieto, M. Pineda, and M. Aguilar, "Spectrophotometric quantitation of antioxidant capacity through the formation of a phosphomolybdenum complex: specific application to the determination of vitamin E," Analytical Biochemistry, vol. 269, no. 2, pp. 337-341, 1999.

[39] C. Wan, Y. Yu, S. Zhou, W. Liu, S. Tian, and S. Cao, "Antioxidant activity and free radical-scavenging capacity of Gynura divaricata leaf extracts at different temperatures," Pharmacognosy Magazine, vol. 7, no. 25, p. 40, 2011.

[40] R. L. Heath and L. Packer, "Photoperoxidation in isolated chloroplasts," Archives of Biochemistry and Biophysics, vol. 125, no. 1, pp. 189-198, 1968.

[41] W. Yan, "GGEbiplot-a windows application for graphical analysis of multienvironment trial data and other types of two-way data," Agronomy Journal, vol. 93, no. 5, pp. 1111-1118, 2001.

[42] S. A. Zafar, A. Hameed, M. A. Nawaz et al., "Mechanisms and molecular approaches for heat tolerance in rice (Oryza sativa
L.) under climate change scenario," Journal of Integrative Agriculture, vol. 17, no. 4, pp. 726-738, 2018.

[43] S. A. Zafar, S. S.-e.-A. Zaidi, Y. Gaba et al., "Engineering abiotic stress tolerance via CRISPR/cas-mediated genome editing," Journal of Experimental Botany, vol. 71, no. 2, pp. $470-479,2020$ b.

[44] L. B. Gómez-Luciano, S. Su, C. Wu, and C. Hsieh, "Establishment of a rapid screening method for drought tolerance of rice genotypes at seedling stage," Journal of International Cooperation, vol. 7, pp. 107-122, 2012.

[45] F. Saeidnia, M. M. Majidi, A. Mirlohi, and S. Soltan, "Physiological and tolerance indices useful for drought tolerance selection in smooth bromegrass," Crop Science, vol. 57, no. 1, pp. 282-289, 2017.

[46] B. Singh, K. R. Reddy, E. D. Redoña, and T. Walker, "Screening of rice cultivars for morpho-physiological responses to early-season soil moisture stress," Rice Science, vol. 24, no. 6, pp. 322-335, 2017.

[47] J. Zhang, S. Zhang, M. Cheng et al., "Effect of drought on agronomic traits of rice and wheat: a meta-analysis," International Journal of Environmental Research and Public Health, vol. 15, no. 5, p. 839, 2018.

[48] Y. Jiang, Y. Qiu, Y. Hu, and D. Yu, "Heterologous expression of AtWRKY57 confers drought tolerance in Oryza sativa," Frontiers in Plant Science, vol. 7, p. 145, 2016.

[49] J.-M. Zong, X.-W. Li, Y.-H. Zhou et al., “The AaDREB1 transcription factor from the cold-tolerant plant Adonis amurensis enhances abiotic stress tolerance in transgenic plant," International Journal of Molecular Sciences, vol. 17, no. 4, p. 611, 2016.

[50] A. Ullah, H. Sun, X. Yang, and X. Zhang, "Drought coping strategies in cotton: increased crop per drop," Plant Biotechnology Journal, vol. 15, no. 3, pp. 271-284, 2017.

[51] S. Arteaga, L. Yabor, M. J. Díez, J. Prohens, M. Boscaiu, and O. Vicente, "The use of proline in screening for tolerance to drought and salinity in common bean (Phaseolus vulgaris L.) genotypes," Agronomy, vol. 10, no. 6, p. 817, 2020.

[52] S. Chutipaijit, "Changes in physiological and antioxidant activity of indica rice seedlings in response to mannitol-induced osmotic stress," Chilean Journal of Agricultural Research, vol. 76, no. 4, pp. 455-462, 2016.

[53] T. Sihem, R. J. Antonio, S. Mariam et al., "Effect of drought on growth, photosynthesis and total antioxidant capacity of the saharan plant Oudeneya Africana," Environmental and Experimental Botany, vol. 176, Article ID 104099, 2020.

[54] Y. Cao, Q. Luo, Y. Tian, and F. Meng, "Physiological and proteomic analyses of the drought stress response in Amygdalus Mira (Koehne) Yü et Lu roots," BMC Plant Biology, vol. 17, p. 53, 2017.

[55] G. B. Bhaskara, T.-H. Yang, and P. E. Verslues, "Dynamic proline metabolism: importance and regulation in water limited environments," Frontiers in Plant Science, vol. 6, p. $484,2015$. 